\title{
SIFAT FISIKA KIMIA TANAH ORDO VERTISOL PADA PENGGUNAAN LAHAN PERTANIAN
}

\author{
Novita Anis Sholihah ${ }^{1}$, Dwiyono Hari Utomo ${ }^{2}$, dan Juarti ${ }^{3}$ \\ E-mail: novitaanissholihah@ymail.com,dwiyono.hari.fis@um.ac.id, \\ juarti.fis@um.ac.id
}

\begin{abstract}
This research aims to know the physical and chemical properties of Ordo Vertisol soil in agriculture land used (paddy fields, dry fields, and farms). This research uses survey method that is implemented in the field and laboratory. Samples were obtained by overlaying two maps using Arc-GIS 10.1 software to produce the Land Unit Map, then the sample was taken by using purposive sampling method which consider the land was planted and has decreased of harvested area, or in productivity or the amount of crop production. Descriptive analysis is used to explain the results of the research and the discussion. The results showed that each land unit has high value of COLE and has properties that are supportive and unsupportive for the cultivation of plants, but each land unit has its differences. Land Unit 1A has the highest/fastest permeability because management is done more intensively, by constantly adding organic matter content that makes the soil density low. Land Unit 1B has higher organic matter because when taking the sample, there is still a part of crop residues and grasses on the surface than any other land units. The land management and irrigation also affect the content of organic matter in terms of its preservation. The lowest CEC contained in Land Unit 2 is caused by the content of the clay fraction is lower than other land units. Low organic matter content in Land Unit 2 also affect the low value of CEC, and the density becomes higher. The permeability in Land Unit 2 is also slower because of no management activities in this land. Land Unit 3A has the lowest $\mathrm{pH}$ due to the given of ZA which produces Acid Sulphur on the land. Land Unit 3B have the highest CEC values for the content of the clay fraction is higher and the Montmorillonite mineral on this land has a permanent charge. Organic materials in Land Unit 3B is also the lowest since the land is left empty before planted with soybeans.
\end{abstract}

Keywords: ordo vertisol soil, land usage, land units

\section{PENDAHULUAN}

Tanah Ordo Vertisol merupakan salah satu tanah yang bermasalah dalam pengelolaannya. Tanah ini membutuhkan pengelolaan dengan teknik-teknik tertentu agar tetap produktif dimanfaatkan dalam bidang pertanian. Permasalahan dalam memanfaatkan satuan tanah Ordo Ver-

${ }^{1}$ Guru MTs Wahid Hasyim Bangil

${ }^{2}$ Dosen Jurusan Geografi UM

${ }^{3}$ Dosen Jurusan Geografi UM tisol sangat erat kaitannya dengan sifat kembang kerut tanah yang tinggi. Pengelolaan tanah bermasalah ada enam jenis yaitu: tanah rawan erosi, vertisol, oxisol, psamments, histosols, dan tanah bergaram (Sartohadi, dkk, 2012:170). Permasalahan kembang kerut pada tanah 1 
Novita Anis Sholihah, Dwiyono Hari Utomo, Juarti. Sifat Fisika Kimia Tanah Ordo Vertisol Pada Penggunaan Lahan Pertanian

Ordo Vertisol diakibatkan oleh kandungan mineral liat montmorilonit. Ciri khas Vertisol termasuk kaya kandungan liat yang tersebar merata pada setiap horizon khususnya mineral liat Montmorilonit (Suryatna, 1985:64).

Kabupaten Pasuruan memiliki tanah Ordo Vertisol seluas 5.882,00 ha (Team e-Gov, 2011). Kecamatan Kraton memiliki tanah Ordo Vertisol seluas $2.025 \mathrm{Ha}$ (BPS, 2013:16-17). Berdasarkan Peta Penggunaan Lahan Kabupaten Pasuruan skala 1:250.000, Kecamatan Kraton memiliki jenis penggunaan lahan antara lain sawah, tegal, tanah terbuka yang ditumbuhi rerumputan, perkebunan, permukiman, empang/tambak, bangunan (pabrik), rawa, dan hutan rawa. Lahan sawah yang ada di Kecamatan Kraton hanya terdapat sawah irigasi teknis seluas $2625 \mathrm{Ha}$ (BPS, 2013:246-251).

Jenis tanaman pangan yang ada di Kecamatan Kraton antara lain padi, jagung, kedelai, kacang tanah, buah mangga, kelapa, tebu, kapuk randu, dan jambu mete (BPS, 2013:247-268). Berdasarkan data Dinas Pertanian Tanaman Pangan Kabupaten Pasuruan, terdapat permasalahan pada jenis tanaman padi, jagung, kedelai, mangga, dan tebu kaitannya dengan penurunan luas panen atau jumlah produksi, dan atau produktivitasnya. Keba-nyakan penggunaan lahan pada tanah sawah, tegal, dan kebun di wilayah jenis Tanah Ordo Vertisol membutuhkan pengelolaan tinggi terutama dalam pengelolaan kesuburan tanahnya. Pemanfaatan lahan pertanian yang ada di Kecamatan Kraton memerlukan informasi yang berhubungan dengan ilmu tanah.

Penelitian ini dilakukan pada bulan Desember 2014 di Kecamatan Kraton
Kabupaten Pasuruan, tepatnya pada tanah Ordo Vertisol pada penggunaan lahan bidang pertanian (sawah, tegal, dan kebun). Tanah yang diambil sampel penelitian hanya sebatas pada epipedon (tidak lebih dari $30 \mathrm{~cm}$ dari permukaan tanah). Penelitian ini bertujuan untuk mengetahui sifat fisika dan kimia Tanah Ordo Vertisol pada penggunaan lahan pertanian (sawah, tegal, dan kebun) di Kecamatan Kraton Kabupaten Pasuruan. Sifat fisika yang diteliti yaitu tekstur tanah, struktur tanah, berat isi, berat jenis, porositas, permeabilitas, dan nilai COLE. Sifat fisika yang diteliti yaitu KTK tanah, nilai $\mathrm{pH}$, dan kandungan bahan organik.

\section{METODE}

Desain penelitian menggunakan metode survey yang dilakukan di Kecamatan Kraton Kabupaten Pasuruan. Objek penelitian diperoleh dengan cara overlay Peta Jenis Tanah dan Peta Penggunaan Lahan Kecamatan Kraton menggunakan software Arc-gis 10.1. Hasil overlay yang dijadikan sampel penelitian adalah Tanah Ordo Vertisol, pada penggunaan lahan dikhususkan hanya pada bidang pertanian yaitu sawah, kebun, dan tegal. Hasil overlay dinamakan Peta Satuan Lahan. Pengambilan sampel juga dilakukan secara purposive sampling yang memperhatikan lahan tersebut ditanami dan mengalami penurunan baik luas panen, atau penurunan produktivitas atau penurunan jumlah produksi panen. Data primer diperoleh dari teknik pengumpulan data di lapang-an, uji laboratorium, dan wawancara tak terstruktur, sedangkan data sekunder diperoleh dengan teknik doku- 
mentasi. Penelitian ini menggunakan analisis des-kriptif dimana hasil penelitian yang telah diperoleh, baik hasil observasi, uji laboratorium, maupun hasil analisis diuraikan dan dijabarkan secara jelas dan detail.

\section{HASIL DAN PEMBAHASAN}

\section{Satuan Lahan Daerah Penelitian}

Berdasarkan Peta Satuan Lahan dan purposive sampling, titik pengambilan sampel dilakukan di lima titik satuan lahan (SL), yaitu SL1A, SL1B, SL2, SL3A, dan SL3B.

SL1A merupakan lahan sawah (irigasi teknis) dengan jenis tanaman padi tepatnya pada koordinat UTM WGS 1984 Zone 49 S 704615 9158490. SL1B merupakan lahan sawah (irigasi teknis) dengan jenis tanaman jagung, tepatnya pada Koordinat UTM WGS 1984 Zone 49 S 704621 9158370. SL2 merupakan lahan perkebunan yang ditanami mangga, tepatnya pada koordinat UTM WGS 1984 Zone 49 S 704291 9157814. Lahan perkebunan tersebut merupakan lahan Kebun Percobaan Mangga Kraton yang terletak di Desa Gerongan. SL3A merupakan lahan tegal dengan jenis tanaman tebu, tepatnya pada koordinat UTM WGS 1984 Zone 49 S 703890 9157752. SL3B meru-pakan lahan tegal dengan tanaman kedelai pada koordinat UTM WGS 1984 Zone 49 S 7043269157246.

Sampel tanah pada lahan sawah dengan tanaman padi diambil pada lahan yang sudah dipanen dan masih ada sisa panennya. Lahan sawah dengan tanaman jagung diambil pada saat sawah masih ditanami jagung, disela-sela tanamannya banyak ditumbuhi rumput. Lahan tegal dengan tanaman kedelai diambil ketika petani mulai menanaminya. Lahan tegal dengan tanaman tebu diambil sampelnya pada saat masih banyak sisa panennya, lahan dalam kondisi sudah lama sejak dipanen, sehingga banyak rumput yang tumbuh di samping sisa tanamannya. Lahan kebun tetap ditanami mangga sepanjang tahun. Kondisi lahan pada saat pengambilan sampel dapat dilihat pada lampiran.

\section{Sifat Fisika dan Kimia Tanah}

Berdasarkan hasil uji laboratorium, sifat-sifat tanah pada setiap satuan lahan dapat dilihat pada Tabel 1: 
Novita Anis Sholihah, Dwiyono Hari Utomo, Juarti. Sifat Fisika Kimia Tanah Ordo Vertisol

Pada Penggunaan Lahan Pertanian

Tabel 1. Rekapitulasi Hasil Uji Tanah pada Tiap Satuan Lahan Tahun 2014

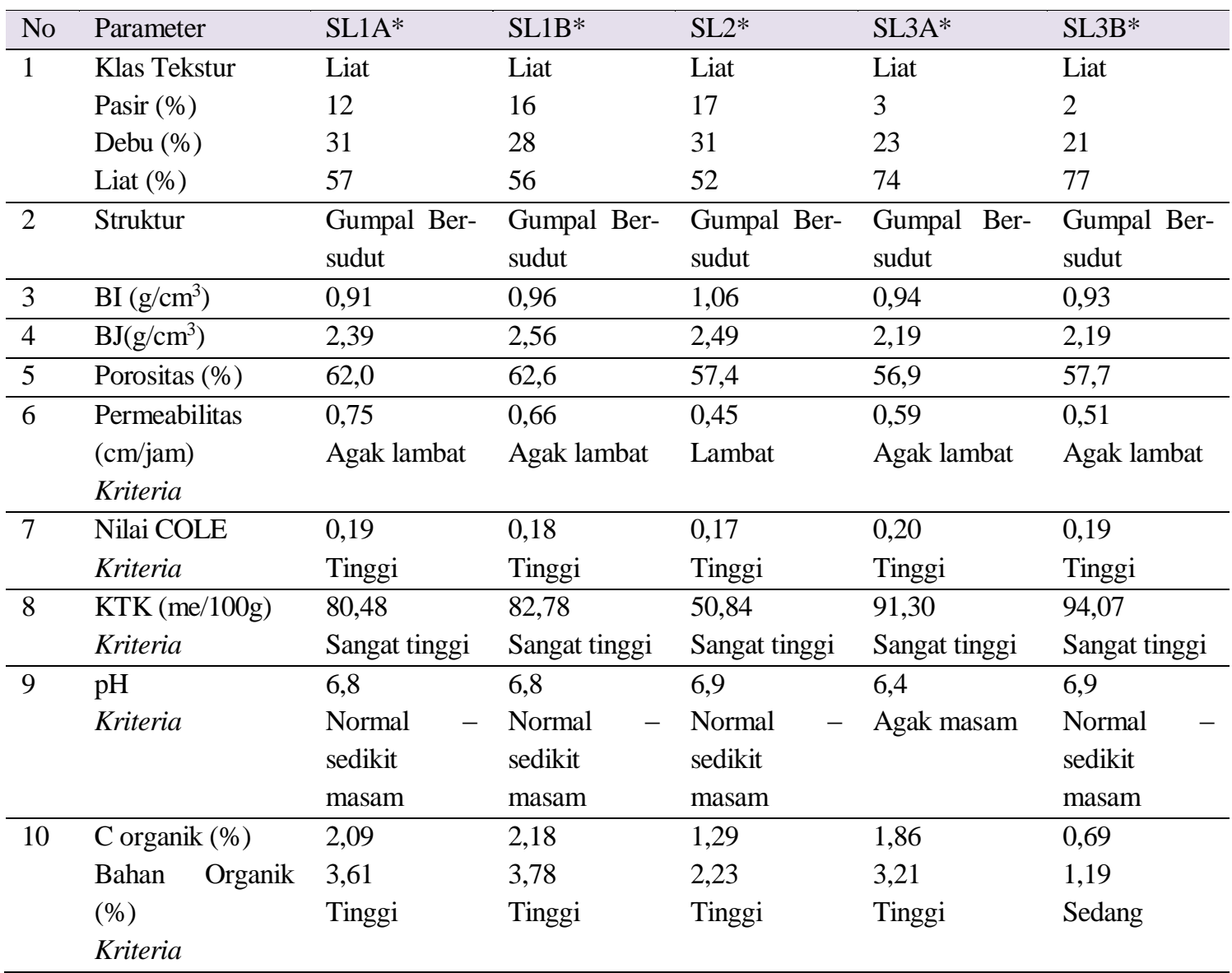

Sumber: Analisis Tanah Desember 2014

Struktur yang sama pada ketiga lahan tersebut juga dipengaruhi oleh karena waktu pengambilan sampelnya sama dan tanahnya sama-sama belum terjadi pengolahan pada lahan sawah, dan tidak terjadi pengolahan atau pengairan yang dapat menyebabkan pelumpuran pada lahan kebun dan tegal. Pengolahan tanah dapat menyebabkan struktur menjadi tidak padat, tetapi karena tidak ada pengolahan praktis pada masing-masing satuan lahan-nya maka tidak ada pengaruh pada struktur lapisan. Pada tanah sawah meskipun yang paling sering mengalami pengolahan, tetapi pada saat pengambilan sampel tidak terjadi pen- golahan sehingga sudah lama tidak ada kegiatan pelumpuran. Kondisi pengairan yang ada pada SL1 kurang intensif atau kurang cukup mengalir seperti tanah sawah irigasi pada umumnya. Jadi pembentukan struktur tanah harus ada pencampuran oleh air, meskipun tanahnya diolah tetapi jika tidak ada pe-ngairan yang cukup tidak akan ada pengaruhnya pada struktur tanah. Hal ini sejalan dengan pendapat Sholah (2014) bahwa struktur lapisan olah dipengaruhi oleh pengolahan praktis, dimana aerasi dan drainase membatasi pertumbuhan tanaman. Rahayu juga mengatakan (2014:79) bahwa struktur tanah, baru terbentuk 
setelah satu sampai tiga bulan tidak disawahkan dan tidak diirigasi.

Masing-masing satuan lahan memiliki sifat tanah yang sama yang mendukung dan kurang mendukung budidaya tanaman. Sifat tanah yang mendukung budidaya tanaman pada masing-masing satuan lahannya yaitu yang berat isinya rendah atau tidak terlalu mampat, sehingga memudahkan sistem perakaran dan penyerapan hara, permeabilitasnya yang baik karena unsur hara yang diberikan tidak mudah diloloskan, KTK tinggi sehingga kemampuannya dalam menyimpan unsur hara relatif baik, nilai $\mathrm{pH}$ normal sehingga unsur hara di dalam tanah dalam keadaan tersedia, serta bahan organiknya tinggi sehingga dapat menentukan status kesuburan tanah. Hal ini sejalan dengan pendapat Soepardi (1983:12) bahwa faktor dalam tanah yang dapat memengaruhi pertumbuhan tanaman selain ketersediaan air dan udara adalah cahaya, tunjangan mekanik atau pengelolaannya, suhu dan unsur hara. Menurut Rachman dkk (2008:7) kesuburan tanah adalah suatu keadaan dimana tata air, udara, dan unsur hara dalam keadaan cukup, seimbang, dan tersedia bagi tanaman.

Sifat tanah yang kurang mendukung untuk dilakukan budidaya tanaman berdasarkan analisis tanah pada 5.2.1, yaitu tekstur tanah yang tidak ideal, strukturnya yang tidak granuler, pori-pori mikronya yang membuat air di dalam tanah tidak semua tersedia bagi tanaman, dan pergerakan udara di dalam tanah kurang. Adanya nilai COLE yang tinggi menyebabkan daya dukung tanah rendah apabila terlalu basah atau terlalu kering, sehingga perlu perhatian lebih terhadap ketersediaan airnya.

Berkaitan dengan sifat yang kurang mendukung ini maka faktor pembatasnya apabila produktivitas menurun hanya ketersediaan air di lahan kebun dan tegal atau kondisi irigasi di lahan sawah. Pertumbuhan tanaman dapat meningkat secara proporsional dengan jumlah air, tetapi pertumbuhan tanaman juga akan terhambat jika jumlah air sangat sedikit atau sangat banyak, apalagi jika tanah pada masing-masing satuan lahannya memiliki nilai COLE yang tinggi. Hal ini sejalan dengan pendapat Winarso (2001:23), bahwa air yang ada pada tanah yang bertekstur sangat halus (liat) tidak semuanya dapat diambil oleh tanaman. Hanafiah (2004:80) juga mengatakan bahwa pada tanah liat meskipun ketersediaan air dan nutrisi baik, namun ketersediaan udara yang menjadi faktor pembatas pertumbuhan tanaman dan mikrobia tanah.

Sifat yang mendukung dan kurang mendukung budidaya tanaman pada masingmasing satuan lahannya secara umum sama, tetapi masing-masing satuan lahannya memiliki sifat yang paling menonjol dibandingkan dengan satuan lahan yang lain.

\section{Satuan Lahan 1 (A)}

Sifat yang membedakan SL1 (A) dengan satuan lahan lainnya yaitu pada lahan ini memiliki nilai permeabilitas yang paling tinggi atau relatif lebih cepat diantara semua satuan lahan. Hal ini dikarenakan pada lahan ini, pengolahan yang dilakukan lebih intensif daripada satuan lahan yang lain. Pengolahan tanah senantiasa menambahkan bahan organik, sehingga bahan organiknya terlapuk dan menjadi humus kemudian membentuk koloid. Koloid humus inilah yang berperan dalam peningkatan permeabilitas. Terbukti dengan bahan organiknya yang 
lebih banyak di lahan sawah. Hal ini sejalan dengan pendapat Rohmat dan Soekarno (2006:5) bahwa terdapat 12 sifat fisik tanah yang diduga berpengaruh terhadap permeabilitas, salah satunya yaitu kandungan bahan organik.

Pengolahan tanah dapat menyebabkan tanah yang padat menjadi berkurang atau sedikit lebih remah, yang berarti akan menyebabkan pori makro bertambah. Sesuai dengan hasil uji laboratorium yang menunjukkan bahwa berat isi pada SL1(A) paling rendah diantara satuan lahan lain karena bahan organiknya yang tinggi. Hal ini sejalan dengan pendapat Foth (1984:63) bahwa kandungan fraksi halus memiliki berat isi yang rendah dan bahan organik yang tinggi.

Sesuai dengan nilai permeabilitas pada lahan ini yang paling tinggi daripada yang lainnya. Semakin cepat atau tinggi nilai permeabilitas tanah, maka berat isinya akan semakin lebih remah atau rendah dan pori makro akan bertambah. Berat isi yang lebih remah atau rendah berarti pada tanah SL1 (A) ini tanahnya tidak lebih padat daripada satuan lahan lain. Penambahan pori tentunya juga dapat menyebabkan permeabilitas yang sa-ngat lambat menjadi berkurang. Hal ini sejalan dengan Sartohadi (2012:47) yang menyatakan bahwa Permeabilitas dapat dipengaruhi oleh keadaan atau ketersediaan pori tanah. Sudaryono (2001:111) juga mengatakan bahwa penurunan permeabilitas tanah disebabkan oleh pemadatan tanah yang ditandai dengan peningkatan berat volume dan penurunan porositas tanah.

\section{Satuan Lahan 1(B)}

Sifat tanah yang membedakan SL1 (B) dengan satuan lahan yang lain adalah bahwa pada lahan ini memiliki kandungan bahan organik yang lebih tinggi. Hal ini dikarenakan pada saat pengambilan sampel tanah pada bagian permukaannya masih terdapat sisa-sisa tanaman sebelumnya, padahal kondisi lahan pada saat pengambilan sampel, tanaman jagung masih belum dipanen dan di sela-sela tanaman lebih banyak ditumbuhi rumput daripada satuan lahan lain. Kegiatan pengolahan dan pengairan pada tanah ini juga berpengaruh terhadap kandungan bahan organik dalam hal pengawetannya. Hal ini sejalan dengan Rahayu (2014:81) bahwa penambahan C organik yang tinggi disebabkan oleh adanya penambahan bahan organik yang berasal dari sisa-sisa tanaman, semakin sering tanah disawahkan dan terbenam, cenderung akan lebih mengawetkan bahan organik.

Kandunggan bahan organik yang paling tinggi dibandingkan dengan satuan lahan lain seharusnya nilai berat jenisnya termasuk yang paling rendah, tetapi yang terjadi justru nilai berat jenis juga merupakan yang paling tinggi. Dimungkinkan lahan sawah ini mendapat efek pemadatan dari petani yang menginjak-injak lahannya, atau pada saat menyemprotkan pestisida karena pada saat pengambilan sampel, tanaman jagung belum dipanen. Hal ini juga dapat terjadi karena kandungan pasir yang menentukan berat jenis. Terbukti dengan nilai kandungan fraksi pasirnya lebih tinggi daripada lahan sawah dengan tanaman padi dan dengan lahan tegal. Semakin tinggi fraksi pasir, berat jenis juga tinggi. Sejalan dengan pendapat Sartohadi, dkk (2012:46) bahwa 
kandungan pasir yang tinggi memiliki berat jenis yang rendah.

\section{Satuan Lahan 2}

Sifat tanah yang membedakan SL2 daripada satuan lahan yang lainnya yaitu KTK pada lahan kebun ini merupakan yang paling rendah karena kandungan fraksi liat pada SL2 juga lebih rendah dari pada satuan lahan lain. Fraksi yang lebih kecil dari liat yaitu koloidnya kurang bisa membentuk KTK yang tinggi. Hal ini sejalan dengan pernyataan Nursyamsi, dan Suprihati (2005:40) bahwa KTK dipengaruhi oleh sumber muatan koloid tanah.

Bahan organik tanah juga menyumbangkan pengaruh terhadap rendahnya KTK pada SL2. Bahan organik pada SL2 lahan kebun termasuk lebih rendah daripada lahan sawah dan tegal dengan tanaman tebu. Bahan organik yang rendah mengakibatkan KTK pada SL2 juga rendah. Hal ini sejalan dengan Leiwakabessy dalam Rachman, dkk (2008:7) yang menyatakan bahwa bahan organik dapat memperbesar kapasitas tukar kation.

KTK tinggi pada SL2 dapat menandakan bahwa mineral liat pada tanah ini memiliki muatan yang bergantung dengan $\mathrm{pH}$, tetapi karena $\mathrm{pH}$ pada tanah ini termasuk normal maka SL2 tidak memiliki muatan yang bergantung dengan $\mathrm{pH}$. Tetapi juga tidak bisa dikatakan bahwa SL2 memiliki muatan permanen karena kandungan KTK tidak lebih dari $80 \mathrm{me} / 100 \mathrm{~g}$ atau $\mathrm{cmol} / 1 \mathrm{Kg}$ yaitu hanya $50,84 \mathrm{me} / 100 \mathrm{~g}$ atau $\mathrm{cmol} / 1 \mathrm{Kg}$. Meskipun jenis tanah objek penelitian termasuk tanah Ordo Vertisol yang memiliki mineral liat Montmorilonit, tidak be- rarti tanah ini memiliki muatan permanen. Menurut Munir (1996:268) muatan permanen pada mineral liat Montmorilonit memiliki KTK antara 80-150 me/100g atau $\mathrm{cmol} / 1 \mathrm{Kg}$.

Berat isi yang dimiliki SL2 juga membedakan dengan satuan lahan yang lain. Berat isi pada tanah ini paling tinggi yang dipengaruhi oleh kandungan bahan organik tanah yang rendah. Bahan organik tanah pada lahan kebun ini lebih rendah daripada di lahan sawah dan tegal dengan tanaman tebu, sehingga berat isinya tinggi. Selain karena bahan organik, tekstur tanah juga berpengaruh terhadap tingginya berat isi. Fraksi pasir pada SL2 memiliki nilai yang paling tinggi daripada satuan lahan lainnya yang dapat menyebabkan berat isinya paling tinggi diantara semua satuan lahan. Hal ini sejalan dengan Foth (1984:63) yang menyatakan bahwa kandungan fraksi halus memiliki berat isi yang rendah dan bahan organik yang tinggi. Soepardi (1983:38) juga menyatakan liat biasanya memiliki berat isi yang lebih rendah daripada pasir.

Selain KTK dan berat isi, permeabilitas pada SL2 juga membedakan dengan satuan lahan lainnya. Permeabilitas pada tanah ini lebih lambat dari satuan lahan lainnya karena di lahan kebun ini tidak ada kegiatan pengolahan. Apalagi jenis tanamannya adalah pohon mangga, berbeda dengan lahan sawah dan tegal yang mendapat perlakuan pengolahan. Pemberian pupuk juga hanya diberikan pada tanah yang melingkari batang pohon saja, sedangkan pengambilan sampel tanah dilakukan relatif jauh dari batang pohon. Sehingga menyebabkan bahan organik pada SL2 lebih sedikit daripada lahan sawah dan tegal dengan tanaman te- 
bu. Hal ini sejalan dengan pernyataan Rohmat dan Soekarno (2006) bahwa terdapat 12 sifat fisik tanah yang diduga berpengaruh terhadap permeabilitas, salah satunya yaitu kandungan bahan organik.

Pengolahan tanah yang hampir tidak ada menyebabkan tanah pada lahan ini lebih padat, yang berarti pori makro tidak bertambah. Sesuai dengan hasil uji laboratorium yang menunjukkan bahwa berat isi pada SL2 paling tinggi diantara satuan lahan lain. Sesuai dengan nilai permeabilitas pada lahan ini yang paling rendah daripada satuan lahan lainnya. Semakin lambat nilai permeabilitas tanah, maka berat isinya akan semakin lebih padat/tinggi dan pori makro akan berkurang. Pori makro yang berkurang tentunya dapat menyebabkan permeabilitas menjadi lambat. Hal ini sejalan dengan pendapat Sartohadi (2012:47) yang menyatakan bahwa Permeabilitas dapat dipengaruhi oleh keadaan atau ketersediaan pori tanah. Sudaryono (2001:111) juga mengatakan bahwa penurunan permeabilitas tanah disebabkan oleh pemadatan tanah yang ditandai dengan peningkatan berat volume dan penurunan porositas tanah.

Permeabilitas yang paling rendah pada SL2 seharusnya memiliki kandungan fraksi liat yang paling tinggi daripada satuan lahan lain, tetapi yang terjadi pada SL2 justru kandungan fraksi liatnya adalah paling rendah. Hal ini dapat terjadi karena peristiwa eluviasi melewati celah tanah yang dibentuk akar tanaman membuat kandungan liat di permukaan lebih rendah. Peristiwa eluviasi ini mengangkut bahan-bahan tanah dari permukaan ke dalam, dan di lahan kebun proses eluviasi ini dibantu oleh air hujan, sehingga ketika tanah permukaan diambil sampelnya, kandungan liatnya berkurang. Hal ini me-nyebabkan pada saat perhitungan permea-bilitas, terjadi percampuran fraksi atau material tanah yang tidak merata. Proses eluviasi tidak akan terjadi jika tidak ada proses hidrolisis. Pada lahan ini mendukung terjadinya eluviasi karena kandungan $\mathrm{pH}$ termasuk normal sedikit masam. Menurut Syekhfani (2013) berpindahnya fraksi liat dari lapisan atas ke lapisan bawah melalui proses eluviasi.

\section{Satuan Lahan 3 (A)}

Sifat tanah yang membedakan SL3 (A) dengan satuan lahan lainnya yaitu nilai $\mathrm{pH}$ tanah yang paling rendah karena pada lahan tegal dengan tanaman tebu ini pupuk yang diberikan adalah pupuk ZA (ZETA). Petani disana biasa membeli pupuk tersebut pada PT. Chiel Jedang Pasuruan di Kecamatan Rejoso. Pupuk ZA mengandung amonium sulfat yang merupakan sumber Nitrogen dan Sulfur bagi tanaman. Sulfur merupakan salah satu zat yang dapat membuat tanah menjadi masam. Hal ini sejalan dengan Hanafiah (2004:159) penurunan pH dapat dilakukan dengan penambahan sulfur atau bahan bersulfur agar sulfur yang dilepaskan membentuk asam sulfur pemasam tanah.

Nilai $\mathrm{pH}$ yang paling rendah diantara semua satuan lahan ini menandakan nilai $\mathrm{pH}$ pada tanah ini dibawah $\mathrm{pH}$ normal karena kurang dari 6,5. Hal ini yang berarti tanah SL3 (A) relatif kurang baik bagi kesuburan tanah. Nilai $\mathrm{pH}$ tanah tersebut berdasarkan klasifikasi keasaman tanah termasuk tanah dengan $\mathrm{pH}$ agak masam. Perlakuan pada tanah ini dapat dilakukan 
pengapuran yang akan menghasilkan ion hidroksil penaik $\mathrm{pH}$ dan kation $\mathrm{Ca}$ peningkat kejenuhan basa, namun disesuaikan juga dengan nilai $\mathrm{pH}$ yang cocok untuk jenis tanaman tebu. Menurut Hanafiah (2004:157) pH normal memiliki rentang nilai 6,5-7,5 yang menyebabkan semua unsur hara dalam larutan tanah dalam keadaan tersedia.

\section{Satuan Lahan 3 (B)}

Sifat tanah yang membedakan SL3 (B) dengan satuan lahan yang lain yaitu nilai KTK pada SL3 (B) merupakan yang paling tinggi daripada semua satuan lahan. Hal ini dikarenakan kandungan fraksi liat pada SL3 (B) juga lebih tinggi daripada satuan lahan lain. Fraksi yang lebih kecil dari liat yaitu koloidnya mampu membentuk KTK yang tinggi. Hal ini sejalan dengan pendapat Nursyamsi dan Suprihati (2005:40) bahwa KTK dipengaruhi oleh sumber muatan koloid tanah.

Kandungan fraksi liat yang paling tinggi pada SL3 (B) seharusnya kandungan bahan organiknya juga tinggi. Tetapi nilai bahan organik pada SL3 (B) merupakan paling rendah diantara semua satuan lahan. Berdasarkan hasil wawancara dan pengamatan di lapangan, perbedaan bahan organik yang terjadi pada lahan tegal dengan tanaman kedelai adalah dikarenakan pada lahan tegal ini tidak ditanami tanaman apapun sebelum ditanami kedelai. Tidak ada sisa-sisa tanaman yang terlihat di tanahnya karena selama musim kemarau tanah dibiarkan kosong. Penanaman kedelai menunggu musim hujan turun dan tidak ada kegiatan pengolahan tanah selama musim kemarau. Sehingga kandungan bahan organik pada tanah ini rendah. Selain itu tidak ada tambahan bahan organik seperti pupuk pada tanah SL3 (B). Hal ini sejalan dengan Rahayu (2014:81) bahwa penambahan $\mathrm{C}$ organik yang tinggi disebabkan oleh adanya penambahan bahan organik yang berasal dari sisa-sisa tanaman, dan semakin sering tanah disawahkan dan terbenam, cenderung akan lebih mengawetkan bahan organik.

Kandungan bahan organik yang paling rendah pada tanah ini seharusnya mampu membuat nilai KTK juga rendah, tetapi kandungan KTK pada tanah ini justru yang paling tinggi. Hal ini berarti bahan organik tidak mampu mengubah nilai KTK tanahnya. KTK tinggi pada SL3 (B) diakibatkan oleh kandungan mineral Montmorilonitnya. Mineral liat pada tanah ini memiliki muatan permanen karena kandungan KTK lebih dari 80 $\mathrm{me} / 100 \mathrm{~g}$ atau $\mathrm{cmol} / 1 \mathrm{Kg}$. Menurut Munir (1996:268) muatan permanen pada mineral liat Montmorilonit memiliki KTK antara $80-150 \mathrm{me} / 100 \mathrm{~g}$ atau $\mathrm{cmol} / 1 \mathrm{Kg}$. Hal ini sejalan dengan Nursyamsi dan Suprihati (2005:40) bahwa sumber muatan pada mineral liat tipe 2:1 didominasi oleh muatan permanen.

\section{PENUTUP}

\section{Kesimpulan}

Masing-masing sifat pada satuan lahannya mendapat pengaruh dari penutup lahan atau pengelolaan tanahnya. SL1A memiliki sifat tanah paling berbeda diantara semua satuan lahan yaitu nilai permeabilitas paling tinggi dan berat isi tanah paling rendah. SL1B memiliki sifat yang paling berbeda yaitu kandungan bahan organik lebih tingg dari semua satuan 
lahan. SL2 memiliki sifat yang paling berbeda yaitu nilai KTK yang paling rendah, berat isi paling tinggi, dan permeabilitas lebih lambat dari semua satuan lahan. SL3A memiliki sifat yang paling berbeda diantara satuan lahan lainnya yaitu nilai $\mathrm{pH}$ tanah yang paling rendah. SL3B memiliki sifat yang membedakan dengan satuan lahan lain yaitu nilai KTK paling tinggi, dan bahan organik paling rendah.

Sifat tanah yang mendukung budidaya tanaman pada masing-masing satuan lahannya yaitu berat isinya yang rendah atau tidak terlalu mampat sehingga memudahkan sistem perakaran dan penyerapan hara, permeabilitasnya yang baik karena hara-hara yang diberikan tidak mudah diloloskan, KTK tinggi sehingga kemampuannya dalam menyimpan unsur hara relatif baik, nilai $\mathrm{pH}$ normal sehingga unsur hara di dalam tanah dalam keadaan tersedia kecuali pada SL3 (A), serta bahan organiknya tinggi sehingga dapat menentukan status kesuburan tanah.

Sifat tanah yang kurang mendukung untuk dilakukan budidaya tanaman yaitu tekstur tanah yang tidak ideal, strukturnya yang tidak granuler, pori mikronya yang membuat air di dalam tanah tidak semua tersedia bagi tanaman dan pergerakan udara di dalam tanah menjadi berkurang. Nilai COLE yang tinggi membuat daya dukungnya rendah apabila terlalu basah atau terlalu kering sehingga perlu perhatian lebih terhadap ketersediaan airnya.

\section{Saran}

Petani di daerah penelitian harus lebih jeli dalam mengolah lahannya terutama pada lahan sawah, karena jenis tanah Ordo Vertisol merupakan tanah yang potensial tetapi dibatasi oleh sifat kembang kerut yang tinggi, jika tidak ada air yang cukup atau terlalu banyak air maka tanaman yang tumbuh diatasnya bisa mati. KTK yang tinggi terkenal pelit dalam hal memberi hara-hara yang dibutuhkan tanaman. Apabila air yang tersedia kurang, justru unsur haranya akan diserap oleh tanah, bukan oleh tanaman.

\section{DAFTAR RUJUKAN}

BPS (Badan Pusat Statistik). 2013. Kabupaten Pasuruan dalam Angka 2013. Pasuruan: katalog BPS 1102001.3514

Foth, Henry D. 1984. Dasar-dasar Ilmu Tanah Edisi Ke Tujuh. Terjemahan Endang Dwi Purbayanti, dkk. 1991. Yogyakarta: Gadjah Madha University Press.

Hanafiah, Kemas Ali. 2004. Dasar-Dasar Ilmu Tanah. Jakarta: Rajagrafindo Persada

Munir, Moch. 1996. Geologi dan Mineralogi Tanah Liat. Jakarat: PT Dunia Pustaka Jaya

Nursyamsi, Dedi, dan Suprihati. 2005. Sifat-sifat Kimia dan Mineralogi Tanah serta Kaitannya dengan Kebutuhan Pupuk untuk Padi, Jagung, dan Kedelai. Jurnal Bul.Agron, (online), Vol. 33 No.3:40-47, (http://repository.ipb.ac.id/handle/1 23456789/35531), diakses tanggal 20 Maret 2015

Rahayu, Ayyu, dkk. 2014. Karakteristik dan Klasifikasi Tanah pada Lahan Kering dan Lahan yang disawahkan di Kecamatan Perak Kabupaten Jombang. Jurnal Tanah dan Sumberdaya Lahan, (online), Vol 1 No.2:77-87, (http://jtsl.ub.ac.id/index.php/jtsl/art 
icle/view/115/126) diakses tanggal 25 Februari 2015.

Rachman, Idris Abd, dkk. 2008. Pengaruh Bahan Organik dan Pupuk NPK terhadap Serapan Hara dan Produksi Jagung di Inceptisol Ternate. Jurnal Tanah dan Lingkungan, (online), Vol 10 No 1:7-13, (http://

soil.ipb.ac.id/jtl/images/art/ART_JT

L_10_1_2.pdf) diakses tanggal 25 Januari 2015.

Rohmat, Dede, dan Soekarno, Indratmo. 2006. Formulasi Efek Sifat Fisik Tanah terhadap Permeabilitas dan Suction Head Tanah. Jurnal Bionatura, (online), Vol.8 No.1, (http://file.upi.edu....), diakses tanggal 20 Maret 2015.

Sartohadi, Junun, dkk. 2012. Pengantar Geografi Tanah. Yogyakarta: Pustaka Belajar.

Sholah. 2014. Ilmu Pertanian- Tanah Pengaruh Pengolahan Tanah terhadap Struktur Tanah, (online), (http://www.caragampang.com), diakses tanggal 20 Februari 2015.

Soepardi, Goeswono. 1983. Sifat dan Ciri Tanah. Bogor: IPB.

Sudaryono. 2001. Pengaruh Pemberian Bahan Pengkondisi Tanah terhadap Sifat Fisik dan Kimia Tanah pada Lahan Marginal Berpasir. Jurnal Teknologi Lingkungan, (online), Vol.2 No.1:106-112, (http://ejurnal.bppt.go.id/index.php /JTL/article/download/220/166), diakses tanggal 20 Maret 2015.

Suryatna, Rafi'i, 1985. Ilmu Tanah. Bandung: Penerbit Angkasa.

Syekhfani. 2013. Horizon Agrilik, (online),

(http://syekhfanismd.lecture.ub.ac.i d/tag/eluviasi-iluviasi/), diakses tanggal 20 Maret 2015.

Team e-Gov. 2011. Gambaran Umum, (online),

(http://bpbd.pasuruankab.go.id), diakses tanggal 9 Juni 2014.

Winarso, Sugeng. 2001. Kesuburan Tanah. Yogyakarta: Gava Media. 